\title{
Xiaokening stimulates endothelial nitric oxide release in diabetic rats
}

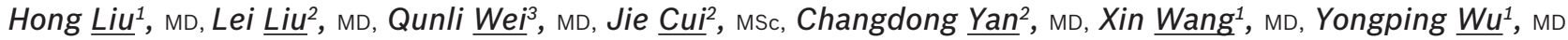

\begin{abstract}
INTRODUCTION Diabetes mellitus induces microangiopathic changes that lead to endothelial dysfunction. This study investigated the effect of Xiaokening, a type of Chinese compound medicine, on the mesenteric arteriolar endothelial cell function of diabetic rats and its underlying mechanism.

METHODS Diabetes mellitus was induced in rat models via intraperitoneal injection of $60 \mathrm{mg} / \mathrm{kg}$ streptozotocin and observed over three weeks. Mesenteric arterioles, which were isolated in a cannulated and pressurised state, were incubated with intravascular injections of 1,3 or $5 \mathrm{~g} / \mathrm{L}$ Xiaokening for 24,48 or 72 hours. The effects of Xiaokening on the release of nitric oxide (NO) on the mesenteric arterioles were detected under shear stress of 1,10 and $20 \mathrm{dyn} / \mathrm{cm}^{2}$. Biochemical methods were used to determine the activities of superoxide dismutase (SOD) and xanthine oxidase (XO). The expressions of endothelial NO synthase (eNOS), SOD and XO in the mesenteric arterioles were assessed using Western blot.

RESULTS Compared to normal rat arterioles, less NO was released in the mesenteric arterioles of diabetic rats. Xiaokening was found to have a concentration- and time-dependent effect on NO release; when the shear stress was increased, there was a gradual increase in the release of NO. Compared to normal arterioles, the expression of eNOS in the mesenteric arterioles of diabetic rats was lower. Incubation with Xiaokening increased SOD activity and expression, and decreased XO activity and expression in the mesenteric arterioles of the diabetic rats.

CONCLUSION Xiaokening was able to significantly increase NO release and improve the endothelial function of mesenteric arterioles through antioxidative mechanisms.
\end{abstract}

Keywords: diabetes mellitus, endothelial cells, nitric oxide, Xiaokening

\section{INTRODUCTION}

Diabetes mellitus is a group of metabolic diseases that is characterised by high blood sugar levels. This occurs either because the body does not produce enough insulin or because cells do not respond to the insulin that is produced. In the past few decades, many studies have shown a clear worldwide increase in the incidence of both type 1 and type 2 diabetes mellitus. ${ }^{(1)}$ Without proper treatment, diabetes mellitus can cause many long-term complications, including cardiovascular disease, chronic renal failure, blindness and nerve damage. Microangiopathy, which is caused by vascular endothelial cell injury and dysfunction, is a fundamental process in diabetes mellitus complications. ${ }^{(2-4)}$ Drug interventions are needed to treat these microvascular complications.

Reactive oxygen species (ROS) play a crucial role in the pathogenesis of some diseases (e.g. cancer, cardiovascular disease, diabetes mellitus and inflammation). ${ }^{(5)}$ The effect of the increased production of free radicals in diabetes mellitus is devastating and well documented. ${ }^{(6-8)}$ Streptozotocin (STZ)induced diabetic rats are one of the animal models for type 1 diabetes mellitus. ${ }^{(9)}$ In type 1 diabetes mellitus, destruction of the $\beta$-cells of the islets of Langerhans causes degranulation or reduction of insulin secretion, but not the total absence of insulin in blood. ${ }^{(10)}$ The cytotoxic action of STZ is associated with the generation of ROS, which causes oxidative tissue damage. ${ }^{(11)}$ There is considerable evidence of the role of altered antioxidant defences (including both nonenzymatic and enzymatic antioxidant systems) and free radicals in the aetiology of diabetes mellitus. ${ }^{(12,13)}$

Many studies have reported that the use of traditional Chinese medicines not only helps to lower serum glucose, but also helps to inhibit the development of diabetic complications. ${ }^{(14,15)}$ Our previous research, which was conducted on umbilical vein endothelial cells (ECV-304), found that Xiaokening effectively reduces cellular injury and proliferation inhibition resulting from high glucose serum levels. ${ }^{(16,17)}$ In other words, Xiaokening was found to have protective effects for endothelial cells and the ability to improve cell propagation. These findings indicate that Xiaokening has a positive effect on endothelial cells in vitro. However, there is little information on the effect of Xiaokening on endothelial cells within vessels. As the effect of Xiaokening on diabetic arterioles has not been reported, the aim of the present study was to explore its effect on the mesenteric arteriolar endothelial cell function of diabetic rats and the underlying mechanism.

\section{METHODS}

STZ and 2,3-diaminonaphthalene (DAN) were purchased from Sigma Chemical Company, MO, USA. The STZ was dissolved in a solution of cold citrate buffer $(0.1 \mathrm{M}, \mathrm{pH} 4.5)$. The DAN was dissolved in methanol. The STZ and DAN solutions used in the present study were freshly dissolved and shielded from light. Antibody for endothelial nitric oxide synthase (eNOS) was purchased from Santa Cruz Biotechnology, TX, USA. The kits for

${ }^{1}$ Department of Pathology, ${ }^{2}$ Department of Physiology, ${ }^{3}$ School of Pharmacy, Xuzhou Medical College, China

Correspondence: Prof Wu Yongping, Professor, Department of Pathology, Xuzhou Medical College, 209 Tongshan Road, Xuzhou 221004 , Jiangsu, China. yongpingwu1957@gmail.com 
measuring superoxide anion $\left(\mathrm{O}_{2}^{-}\right)$content, superoxide dismutase (SOD) activity and xanthine oxidase (XO) activity were from Nanjing Jiancheng Bioengineering Institute, Nanjing, China. Xiaokening (national patent no. 200410064899X) is composed of prepared rhubarb, radix aconiti lateralis preparata and crude radix astragali. It is an alcohol extract prepared via fractionation by column chromatography followed by high performance liquid chromatography-mass spectrometry. The Xiaokening used in the present study was made by the School of Pharmacy, Xuzhou Medical College, China.

Male Sprague-Dawley rats that weighed about $200 \mathrm{~g}$ were obtained from the Experimental Animal Center, Xuzhou Medical College, China. All animal procedures were performed with the approval of the Ethics Committee for the Use of Experimental Animals of Xuzhou Medical College, China (SCXK2010-0003). The rats were divided into two groups: the control group $(n=6)$ and the STZ-induced diabetic group $(n=24)$. After overnight fasting (i.e. the rats were deprived of food for 12 hours but given free access to water), diabetes mellitus was induced via an intraperitoneal (IP) injection of STZ at a dose of $60 \mathrm{mg} / \mathrm{kg}$. The blood glucose concentrations of these STZ-treated rats were determined on the 7 th, 14 th and 21 st day after the injection. The rats that had blood glucose levels that were greater than $11.1 \mathrm{mmol} / \mathrm{L}$ were considered diabetic and detained for the experiments. Rats in the control group received $60 \mathrm{mg} / \mathrm{kg} \mathrm{IP}$ injection of citrate buffer.

The STZ-induced diabetic rats and control rats were anaesthetised with $10 \%$ chloral hydrate $(400 \mathrm{mg} / \mathrm{kg}$ IP) on the 21 st day. Experiments were conducted on arterioles that were isolated from the rat's mesentery. About 10-mm lengths of first-order mesenteric arterioles that had diameters of about $300 \mu \mathrm{m}$ were obtained and used as detector vessels. Mesenteric arterioles were used because a sufficient number of vessels can be obtained from the mesentery for biochemical analysis and Western blot.

All perfusion chambers, tubing, reservoirs and connectors were autoclaved prior to use. The perfusion system was placed in a vertical cell culture hood in order to maintain a sterile environment. The perfusion system consists of four 1-mL perfusion chambers that provide an identical experimental environment for four single vessels. The intravascular pressure of the vessels was maintained by four separate pressure reservoirs. The height of the reservoirs was precisely controlled.

In the present study, the isolated first-order mesenteric arterioles of the control and STZ-induced diabetic rats were cultured in perfusion chambers using Dulbecco's Modified Eagle's Medium (DMEM). To observe the effect of Xiaokening on the arterioles of STZ-induced diabetic rats, 1, 3 and $5 \mathrm{~g} / \mathrm{L}$ of Xiaokening were injected into the arterioles of these rats using a microelectrode and the arterioles were placed in an incubator for 24,48 or 72 hours. The DMEM and intravascular Xiaokening mixture was changed once every four hours.

Nitrite is an existing form of nitric oxide $(\mathrm{NO})$ in physiological saline solution. It reacts with DAN to form 1-(H) naphthoteiazole, which fluoresces when its molecules are excited at $375 \mathrm{~nm}$ (emission is collected at $415 \mathrm{~nm}$ ). Similar to that which was done in our previous study, ${ }^{(18)}$ the first-order arteries were incubated with Xiaokening for 24, 48 or 72 hours in a vessel chamber with DMEM before being perfused with a MOPS (comprising $142 \mathrm{mmol} / \mathrm{L} \mathrm{NaCl}, 5.0 \mathrm{mmol} / \mathrm{L} \mathrm{KCl}, 2.0 \mathrm{mmol} / \mathrm{L} \mathrm{CaCl}_{2}, 1.2 \mathrm{mmol} / \mathrm{L}$ $\mathrm{MgSO}_{4^{\prime}}, 1.2 \mathrm{mmol} / \mathrm{L} \mathrm{NaH}{ }_{2} \mathrm{PO}_{4^{\prime}} 5.0 \mathrm{mmol} / \mathrm{L}$ glucose, $2.0 \mathrm{mmol} / \mathrm{L}$ pyruvate, $0.2 \mathrm{mmol} / \mathrm{L}$ EDTA and $3.0 \mathrm{mmol} / \mathrm{L} 3$-[N-morpholino] propanesulphonic acid)-buffered physiological salt solution for $\mathrm{NO}$ release measurements. After the internal diameter and length of the vessels were measured under a microscope, wall shear stress of 1, 10 and $20 \mathrm{dyn} / \mathrm{cm}^{2}$ were established by increasing perfusate flow using a syringe pump that was connected to an in-line pressure transducer that monitors inflow pressure. The outflow pressure was adjusted accordingly to maintain constant intravascular pressure. Perfusate $(400 \mu \mathrm{L})$ at the outflow tubing was collected at each level of shear stress. Standard curves of nitrite $(0-640 \mu \mathrm{M})$ were constructed using MOPS as a vehicle and $\mathrm{NO}$ level was expressed as fluorescence intensity. Nitrite production in response to shear stress was expressed as $\mathrm{pmol} / \mathrm{mm}^{2}$ of the lumen surface of the arterioles per minute.

After perfusion, three or four mesenteric arteries were collected and homogenated. The protein concentration in the supernatant was determined using the bicinchoninic acid assay (Nanjing Jiancheng Bioengineering Institute, Nanjing, China). $\mathrm{O}_{2}{ }^{-}$content, and SOD and $\mathrm{XO}$ activities were assayed according to the commercial kits' manuals (Nanjing Jiancheng Bioengineering Institute, Nanjing, China). $\mathrm{O}_{2}{ }^{-}$content was expressed as unit/g protein, while SOD and $\mathrm{XO}$ activities were expressed as unit/ mg protein.

The arteries were pulverised in liquid nitrogen after perfusion and the samples were solubilised in a lysis buffer in ice for 30 minutes, followed by two one-minute sonications with a five-minute interval. The mesenteric arterioles were isolated and pooled to denature the proteins. Samples containing $10 \mu \mathrm{g}$ of protein were separated on sodium dodecyl sulphatepolyacrylamide gel electrophoresis (SDS-PAGE) gels (10\% acrylamide) and transferred to a polyvinyl difluoride membrane. The membrane was then probed with primary antibodies for eNOS. Secondary antibodies were conjugated to horseradish peroxidase, according to the NBT/BCIP protocol. $\beta$-actin was used to normalise for loading variations.

Data was presented as mean \pm standard error. Statistical significance was assessed using one-way analysis of variance (ANOVA), followed by a post hoc (Bonferroni) test for a multiple group comparison. Differences that had a p-value $<0.05$ were considered statistically significant.

\section{RESULTS}

To investigate the effect Xiaokening has on the endothelial function of arteries in STZ-induced diabetic rats, the mesenteric arterioles of the rats were isolated and incubated with or without Xiaokening for 24,48 or 72 hours. NO release from the arterioles was then assessed during the induction of different shear stress pressures $\left(1,10\right.$ and $20 \mathrm{dyn} / \mathrm{cm}^{2}$ ). The NO release in response to shear stress was lower in the arterioles from the STZ-induced 


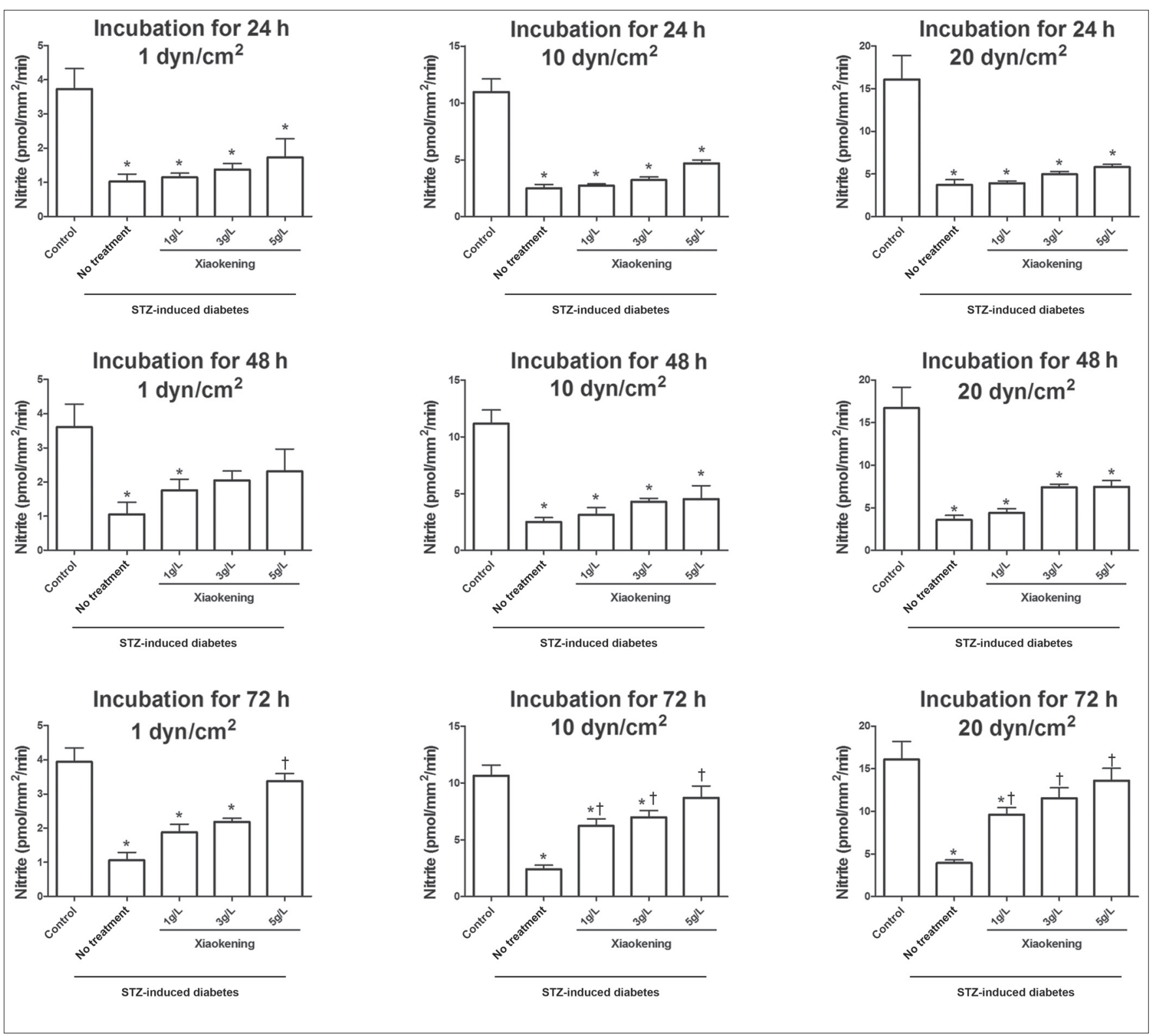

Fig. 1 Bar graphs show the effect of Xiaokening on shear stress $\left(1,10\right.$ and $\left.20 \mathrm{dyn} / \mathrm{cm}^{2}\right)$. There was an increase in the induced perfusate nitrite among the isolated mesenteric arterioles of the streptozotocin (STZ)-induced diabetic rats after 24,48 and 72 hours of Xiaokening treatment. Data shown as mean \pm standard error, $n=6$ per group. ${ }^{*} p<0.05$ vs. control group; ${ }^{\dagger} p<0.05$ vs. STZ-induced diabetic group.

diabetic rats as compared to that of the arterioles from the control group (Fig. 1, p < 0.05). Xiaokening (1, 3 or 5 g/L) was found to have a concentration- and time-dependent effect on $\mathrm{NO}$ release in the arterioles. Incubation with $5 \mathrm{~g} / \mathrm{L}$ Xiaokening for 72 hours had the best effect in reversing shear stress-induced NO release in arterioles from STZ-induced diabetic rats. Therefore, we used $5 \mathrm{~g} / \mathrm{L}$ Xiaokening and 72-hour incubation to explore the underlying mechanism through which Xiaokening protects arteriole endothelial function in these rats.

Compared to the arterioles of the control group, eNOS expression was significantly lower in the mesenteric arterioles of the STZ-induced diabetic rats $(p<0.05)$. Incubation with $5 \mathrm{~g} / \mathrm{L}$ Xiaokening for 72 hours reversed the decrease in eNOS expression in the arterioles of STZ-induced diabetic rats (Fig. 2).

It is well known that diabetes-induced endothelial cell damage is caused by oxidative stress. In the present study, we found that $\mathrm{O}_{2}$ - content in the arterioles of STZ-induced diabetic rats was significantly greater than that in the arterioles of the control rats (Fig. 3). Incubation with $5 \mathrm{~g} / \mathrm{L}$ Xiaokening for 72 hours significantly decreased the $\mathrm{O}_{2}$ - content in the arterioles of the diabetic rats. This indicates that Xiaokening reverses diabetesinduced endothelial damage by removing $\mathrm{O}_{2}$.

SOD is responsible for destroying free superoxide radicals in the body. As shown in Fig. 4, reduced expression and activity of manganese-SOD in the arterioles of STZ-induced diabetic rats were significantly reversed with Xiaokening treatment. $\mathrm{XO}$ is an oxidase which that produces reactive oxygen species. Incubation with $5 \mathrm{~g} / \mathrm{L}$ Xiaokening for 72 hours also significantly decreased XO expression and activity (Fig. 4), indicating that Xiaokening suppressed diabetes-induced upregulation of $\mathrm{XO}$ expression and activity. These results suggest that changes in SOD and XO activity and expression are the mechanisms by 


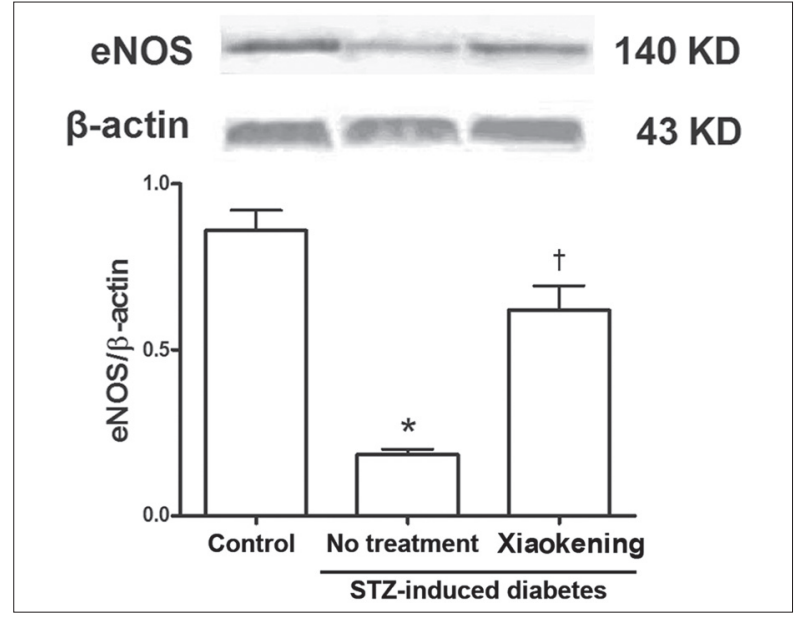

Fig. 2 Representative Western blot shows endothelial nitric oxide synthase (eNOS) protein from the isolated mesenteric arterioles of rats from the control group and the streptozotocin (STZ)-induced diabetic group, with and without treatment with $5 \mathrm{~g} / \mathrm{L}$ Xiaokening for 72 hours. Data is normalised by means of densitometric ratios of eNOS and $\beta$-actin, and shown as mean \pm standard error, $n=3$ per group. ${ }^{*} p<0.05$ vs. control group; ${ }^{\dagger} p<0.05$ vs. STZ-induced diabetic group.

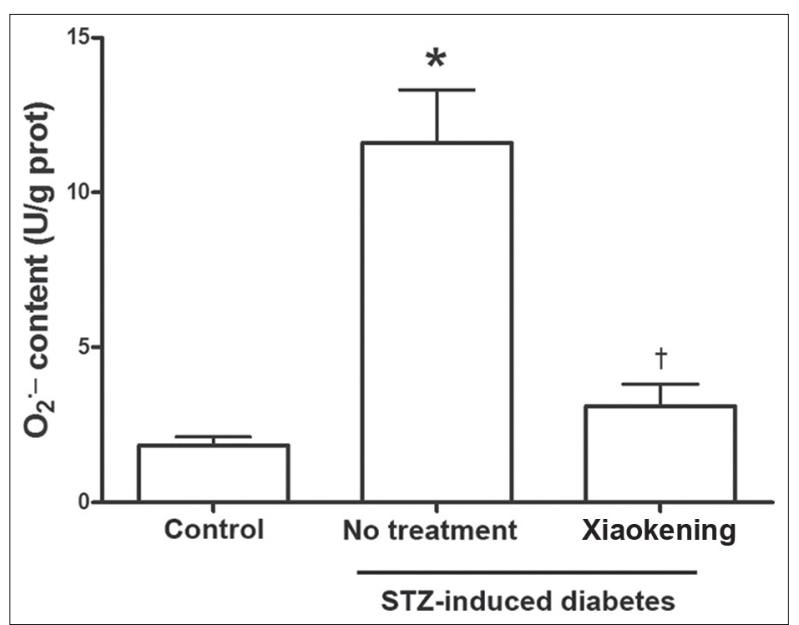

Fig. 3 Bar graph shows that $5 \mathrm{~g} / \mathrm{L}$ of Xiaokening treatment for 72 hours inhibits the increase of $\mathrm{O}_{2}$ in the isolated mesenteric arterioles of streptozotocin (STZ)-induced diabetic rats. Data is shown as mean \pm standard error, $n=6$ per group. ${ }^{*} p<0.05$ vs. control group; ${ }^{\dagger} p<0.05$ vs. STZ-induced diabetic group. eNOS: endothelial nitric oxide synthase

which Xiaokening decreases $\mathrm{O}_{2}$-activity in STZ-induced diabetic arterioles.

\section{DISCUSSION}

In the present study, we found that Xiaokening evoked a concentration- and time-dependent effect on NO release. This effect is related to the reversion of eNOS expression by Xiaokening in the arterioles of STZ-induced diabetic rats, which can be explained by the effect of Xiaokening on XO and SOD expression and activity.

Endothelial dysfunction is considered to be the primary cause of vascular disease in diabetes mellitus. ${ }^{(2,19-21)}$ It is characterised by an impaired vascular response to endothelium-derived $\mathrm{NO} .^{(22)}$ $\mathrm{NO}$, a major vasoactive substance released by the endothelium, plays an important role in the regulation of a stable internal environment. ${ }^{(23)}$ This regulation involves several physiological and pathological processes, such as the inhibition of neutrophil chemotaxis, the aggregation and adhesion to the vascular endothelium, the inhibition of vascular smooth muscle cell proliferation and migration, the inhibition of the adhesion of monocytes and platelets and the stimulation of endothelial cell growth. The present study found that when shear stress increased gradually from $1 \mathrm{dyn} / \mathrm{cm}^{2}$ to $20 \mathrm{dyn} / \mathrm{cm}^{2}$, NO released from the arteriolar endothelial cells gradually increased in both the control rats and the STZ-induced diabetic rats (Fig. 1). Reduced $\mathrm{NO}$ release in diabetes mellitus damages the dilation function of arterioles. ${ }^{(24,25)}$

Chinese medicines have been found to have the ability to prevent and treat diabetic nephropathy in the early stages; ${ }^{(26-29)}$ this may be due to the fact that they are often made of diverse effective components, which are able to act on different targets of diabetic nephropathy. The compound preparation Xiaokening is composed of extractions of rhubarb, radix aconiti lateralis preparata and crude radix astragali. In previous studies, we showed that Xiaokening has positive effects in regulating diabetes mellitus and diabetic nephropathy. ${ }^{(30-32)}$ In the present study, we found that Xiaokening (1, 3 or $5 \mathrm{~g} / \mathrm{L}$ for 24,48 or 72 hours) evoked a concentration- and time-dependent effect on the NO release of arterioles (Fig. 1). This observed increase in $\mathrm{NO}$ release from arteriolar endothelial cells that were treated with Xiaokening suggests that it can improve microvascular function in diabetes mellitus. In the present study, incubation with $5 \mathrm{~g} / \mathrm{L}$ Xiaokening for 72 hours was the most effective in reversing the effect of shear stress on NO release in the arterioles of STZ-induced diabetic rats. Therefore, incubation with $5 \mathrm{~g} / \mathrm{L}$ Xiaokening for 72 hours was used to explore the underlying mechanism through which Xiaokening protects arteriolar endothelial function in these rats.

eNOS conjugates tetrahydrobiopterin $(\mathrm{BH} 4)$ and L-arginine to promote the synthesis of $\mathrm{NO}$ in endothelial cells; it is the main source of $\mathrm{NO}$ under physiological conditions. ${ }^{(33,34)}$ Excessive generation of reactive oxygen species is known to impair eNOS activity and NO production, thereby affecting endotheliumdependent vasodilation. ${ }^{(35)}$ In the present study, we found lower eNOS expression in the arterioles of the STZ-induced diabetic rats, but this decrease could be reversed with Xiaokening treatment. This finding indicates that Xiaokening enhances NO release from arteriolar endothelial cells via upregulation of eNOS expression.

Chronic hyperglycaemia can cause oxidative stress, which can then result in cellular tissue damage. The structure and function of an organ can be disturbed during uncontrolled hyperglycaemia. ${ }^{(8)}$ Several studies have shown that diabetes mellitus (both type I and type II) is accompanied by an increased formation of free radicals and a decreased antioxidant capacity, resulting in oxidative damage to cell components. ${ }^{(36)}$ STZ has cytotoxic effects against various vital tissues of the pancreas, liver and kidney. STZ-induced diabetes mellitus is associated with the generation of ROS, which causes oxidative damage ${ }^{(8,37)}$ and ROS formation plays a major role in diabetes-induced endothelial dysfunction. ${ }^{(38,39)}$ In the present study, we found that Xiaokening significantly reduced diabetes-induced elevation of $\mathrm{O}_{2}^{-}$. This 


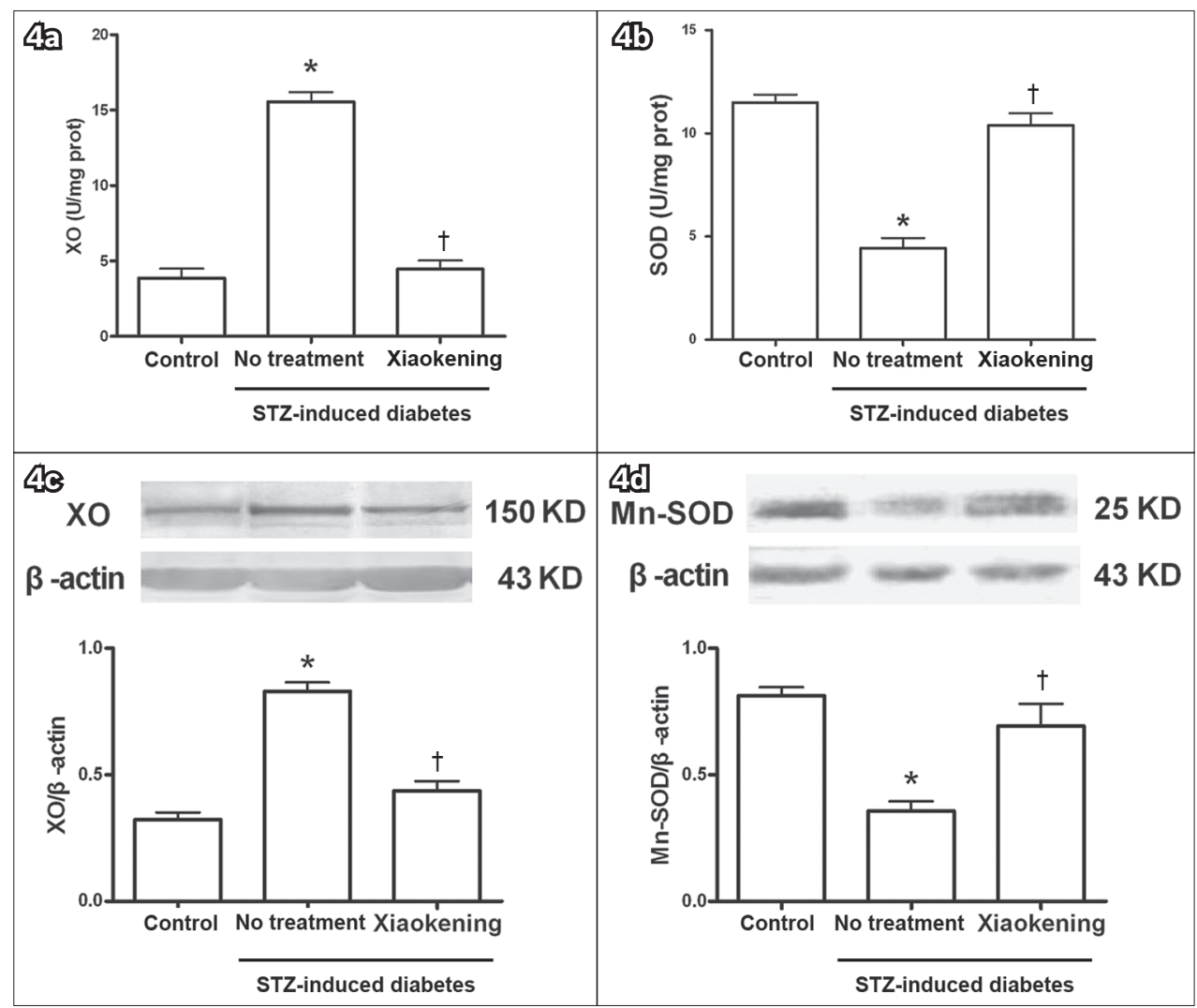

Fig. 4 Bar graphs show the changes in xanthine oxidase (XO) and manganese-superoxide dismutase (Mn-SOD) expression and activity before and after treatment with $5 \mathrm{~g} / \mathrm{L}$ Xiaokening for 72 hours. Data is shown as mean \pm standard error, $n=6$ per group (in $a \& b$ ), $n=3$ per group (in $c \& d$ ). ${ }^{*} p<0.05$ vs. control group; $t p<0.05$ vs. streptozotocin (STZ)-induced diabetic group.

finding suggests that Xiaokening may have the ability to protect arterioles against the cytotoxic action of STZ.

Oxidative stress, or an increase in the level of ROS, in the biological system is known to occur due to increased activity of ROS-generating systems and/or decreased antioxidant defence mechanisms. ${ }^{(40)} \mathrm{XO}$ is an oxidase that produces reactive oxygen species while SOD, an endogenous scavenger of superoxide, is responsible for destroying free superoxide radicals in the body. In the present study, incubation with $5 \mathrm{~g} / \mathrm{L}$ Xiaokening for 72 hours reversed $X O$ and SOD expression and activity in the arterioles of STZ-induced diabetic rats. The most effective defence mechanism against diseases such as diabetes mellitus is the removal of $\mathrm{O}_{2}$. The findings of the present study reveal that Xiaokening may be able to balance the oxidative system and thus prevent pathological alterations caused by $\mathrm{O}_{2}$. Imbalance between the oxidant and antioxidant system will increase ROS generation and result in $\mathrm{BH} 4$ depletion and eNOS uncoupling. ${ }^{(41)}$ Decreased synthesis and release of NO will then lead to endothelium dysfunction in diabetes mellitus. The results of the present study suggest that Xiaokening is an effective antioxidant that is able to protect arteriolar endothelial function against diabetes-induced endothelial damage. However, this study was practiced in isolated and cultured vessels, and it is still necessary to observe the effect of Xiaokening on diabetic vessels in vivo. Further studies are also needed to expand on and demonstrate the underlying molecular mechanisms of this protective effect.
In conclusion, the results of the present study show that Xiaokening can increase endothelial NO release and improve endothelial function through the inhibition of $\mathrm{O}_{2}$ - increase in diabetes mellitus. Our findings suggest that Xiaokening has the potential to be developed as a drug for the treatment of diabetesinduced vascular disease.

\section{REFERENCES}

1. Guerci B, Böhme P, Kearney-Schwartz A, Zannad F, Drouin P. Endothelial dysfunction and type 2 diabetes. Part 2: altered endothelial function and the effects of treatments in type 2 diabetes mellitus. Diabetes Metab 2001; 27(4 Pt 1):436-47.

2. Schalkwijk CG, Stehouwer CD. Vascular complications in diabetes mellitus: the role of endothelial dysfunction. Clin Sci (Lond) 2005; 109:143-59.

3. Spinetti G, Kraenkel N, Emanueli C, Madeddu P. Diabetes and vessel wall remodelling: from mechanistic insights to regenerative therapies. Cardiovasc Res 2008; 78:265-73.

4. Coccheri S. Approaches to prevention of cardiovascular complications and events in diabetes mellitus. Drugs 2007; 67:997-1026.

5. Halliwell B. Free radicals and antioxidants: updating a personal view. Nutr Rev 2012; 70:257-65.

6. Afanas'ev I. Signaling of reactive oxygen and nitrogen species in Diabetes mellitus. Oxid Med Cell Longev 2010; 3:361-73.

7. Dröge W. Free radicals in the physiological control of cell function. Physiol Rev 2002; 82:47-95.

8. Sellamuthu PS, Arulselvan P, Kamalraj S, Fakurazi S, Kandasamy M. Protective nature of mangiferin on oxidative stress and antioxidant status in tissues of streptozotocin-induced diabetic rats. ISRN Pharmacol 2013; 2013:750109.

9. Maiti R, Das UK, Ghosh D. Attenuation of hyperglycemia and hyperlipidemia in streptozotocin-induced diabetic rats by aqueous extract of seed of Tamarindus indica. Biol Pharm Bull 2005; 28:1172-6.

10. Rustenbeck I, Wienbergen A, Bleck C, Jörns A. Desensitization of 
insulin secretion by depolarizing insulin secretagogues. Diabetes 2004; 53 Suppl 3:S140-50.

11. Szkudelski T. The mechanism of alloxan and streptozotocin action in B cells of the rat pancreas. Physiol Res 2001; 50:537-46.

12. Raza H, Prabu SK, John A, Avadhani NG. Impaired mitochondrial respiratory functions and oxidative stress in streptozotocin-induced diabetic rats. Int J Mol Sci 2011; 12:3133-47.

13. Wei W, Liu Q, Tan Y, et al. Oxidative stress, diabetes, and diabetic complications. Hemoglobin 2009; 33:370-7.

14. Zhuang BX, Ma LB, Yu CL, et al. [Percutaneous transluminal angioplasty in treatment of lower limb peripheral arterial disease in diabetes patients: analysis of 150 cases]. Zhonghua Yi Xue Za Zhi 2007; 87:1821-4. Chinese.

15. Xiao YL, Lu FE, Xu LJ, Leng SH, Wang KF. [Protective effects of Huanglian Jiedu decoction on vascular endothelial function in type 2 diabetic rats]. Zhongguo Zhong Yao Za Zhi 2005; 30:1767-70. Chinese.

16. Gong YS, Zhao FH, Yan CD, Wei QL, Liu H. [Protective effects of Xiaokening granules on endothelial cells induced by high glucose]. Acta Academ Med Xuzhou 2008; 28:678-81. Chinese.

17. Gong YS, Yan CD, Liu H, Zhao FH, Wei QL. [Protective effects of Xiaokening granules on high glucose induced endothelial cell oxidative stress]. Chin J Integr Tradit Western Nephrol 2008; 9:995-6. Chinese.

18. Yan C, Huang A, Kaley G, Sun D. Chronic high blood flow potentiates shear stress-induced release of $\mathrm{NO}$ in arteries of aged rats. Am J Physio Heart Circ Physiol 2007; 293:H3105-10.

19. Giacco F, Brownlee M. Oxidative stress and diabetic complications. Circ Res 2010; 107:1058-70.

20. Zhong W, Zou G, Gu J, Zhang J. L-arginine attenuates high glucoseaccelerated senescence in human umbilical vein endothelial cells. Diabetes Res Clin Pract 2010; 89:38-45.

21. Ding H, Triggle CR. Endothelial cell dysfunction and the vascular complications associated with type 2 diabetes: assessing the health of the endothelium. Vasc Health Risk Manag 2005; 1:55-71.

22. Brouwers O, Niessen PM, Haenen G, et al. Hyperglycaemia-induced impairment of endothelium-dependent vasorelaxation in rat mesenteric arteries is mediated by intracellular methylglyoxal levels in a pathway dependent on oxidative stress. Diabetologia 2010; 53:989-1000.

23. Avogaro A, Fadini GP, Gallo A, Pagnin E, de Kreutzenberg S. Endothelia dysfunction in type 2 diabetes mellitus. Nutr Metab Cardiovasc Dis 2006; 16 Suppl 1:S39-45.

24. Meyer MF, Lieps D, Schatz H, Pfohl M. Impaired flow-mediated vasodilation in type 2 diabetes: lack of relation to microvascular dysfunction. Microvasc Res 2008; 76:61-5.

25. Wessells H, Teal TH, Engel K, et al. Fluid shear stress-induced nitric oxide production in human cavernosal endothelial cells: inhibition by hyperglycaemia. BJU Int 2006; 97:1047-52.

26. Kan WC, Wang HY, Chien CC, et al. Effects of Extract from Solid-State Fermented Cordyceps sinensis on Type 2 Diabetes Mellitus. Evid Based
Complement Alternat Med 2012; 2012:743107.

27. Song C, Xie C, Zhou Z, Yu S, Fang N. Antidiabetic Effect of an Active Components Group from Ilex kudingcha and Its Chemical Composition. Evid Based Complement Alternat Med 2012; 2012:423690.

28. Zhen Z, Chang B, Li M, et al. Anti-diabetic effects of a Coptis chinensis containing new traditional Chinese medicine formula in type 2 diabetic rats. Am J Chin Med 2011; 39:53-63

29. Fang XK, Gao Y, Yang HY, et al. Alleviating effects of active fraction of Euonymus alatus abundant in flavonoids on diabetic mice. Am J Chin Med 2008; 36:125-40.

30. Wei QL, Lu XH, Xia SH, Liu CP, Liu C. [Effect of Xiaokening on transforming growth factor beta 1 level in early diabetic nephropathy patients]. Chin J Clin Rehab 2006; 10:116-8. Chinese.

31. Wei QL, Lu XH, Tang H, Liu CP, Liu C. [Effect of Xiaokening on adjusting the proliferation of mesangial cells in rats under high glucose]. Chin J Clin Rehab 2006; 10:196-8. Chinese.

32. Wei QL, Lu XH, Tang H, Liu CP, Liu C. [Clinical observation of Xiaokening on prevention and treatment of early diabetic nephropathy]. Chin J Integr Tradit Western Nephrol 2007; 8:280-1. Chinese.

33. Crabtree MJ, Smith CL, Lam G, Goligorsky MS, Gross SS. Ratio of 5,6,7,8-tetrahydrobiopterin to 7,8-dihydrobiopterin in endothelial cells determines glucose-elicited changes in $\mathrm{NO}$ vs. superoxide production by eNOS. Am J Physiol Heart Circ Physiol 2008; 294:H1530-40.

34. Cai S, Khoo J, Channon KM. Augmented $\mathrm{BH} 4$ by gene transfer restores nitric oxide synthase function in hyperglycemic human endothelial cells. Cardiovasc Res 2005; 65:823-31.

35. Srinivasan S, Hatley ME, Bolick DT, et al. Hyperglycaemia-induced superoxide production decreases eNOS expression via AP-1 activation in aortic endothelial cells. Diabetologia 2004; 47:1727-34.

36. Bashan N, Kovsan J, Kachko I, Ovadia H, Rudich A. Positive and negative regulation of insulin signaling by reactive oxygen and nitrogen species. Physiol Rev 2009; 89:27-71.

37. Matsunami T, Sato Y, Hasegawa Y, et al. Enhancement of reactive oxygen species and induction of apoptosis in streptozotocin-induced diabetic rats under hyperbaric oxygen exposure. Int J Clin Exp Pathol 2011; 4:255-66.

38. Pricci F, Leto G, Amadio L, et al. Oxidative stress in diabetes-induced endothelial dysfunction involvement of nitric oxide and protein kinase C. Free Radic Biol Med 2003; 35:683-94.

39. Yu Y, Lyons TJ. A lethal tetrad in diabetes: hyperglycemia, dyslipidemia, oxidative stress, and endothelial dysfunction. Am J Med Sci 2005; 330:227-32.

40. Samuel SM, Thirunavukkarasu M, Penumathsa SV, et al. Thioredoxin-1 gene therapy enhances angiogenic signaling and reduces ventricular remodeling in infarcted myocardium of diabetic rats. Circulation 2010; 121:1244-55.

41. Silberman GA, Fan $\mathrm{TH}$, Liu $\mathrm{H}$, et al. Uncoupled cardiac nitric oxide synthase mediates diastolic dysfunction. Circulation 2010; 121:519-28. 